\title{
COMPARISON OF SURGICAL OUTCOME OF ENDOSCOPIC DACRYOCYSTORHINOSTOMY WITH OR WITHOUT FLAP
}

\author{
Wissam Egab Aziz ${ }^{*}$ \& Ahmed M Al-Abbasi ${ }^{\circledR}$
}

*MB,ChB, FIBMS Specialist in ORL-H\&N Surgery, Basrah Teaching Hospital. ${ }^{\circledR} \mathrm{MB}, \mathrm{ChB}$, FIBMS, FRCS, Professor of ORL-H\&N Surgery, Department of Surgery, College of Medicine, University of Basrah, Basrah, IRAQ.

\begin{abstract}
The goals of this study were to evaluate the results of endoscopic endonasal dacryocystorhinostomy (DCR) and to compare the surgical success rates of the different procedures (with or without mucosal flap) in patients with nasolacrimal duct obstruction.

This prospective study investigated the results of 39 patients, they were 36 females $(92.3 \%)$ and 3 males (7.7\%). Endoscopic endonasal DCR was performed at the Basrah Teaching Hospital, Department of Otolaryngology in the period between July 2018 to July 2019. The patients were divided into two groups; with or without flap. During surgery, the mucosal flap was preserved in 13 patients (group B) and removed in 26 patients (group A). For all patients, silicone stents were put at the end of surgery. The silicone tube was removed within 6 months after surgery.

After six months follow-up, the results were; patent ostium reported in 17 patients $(81 \%)$ in group A and in 10 patients (90.9\%) in group B. There was no statistically significant difference between the groups (P-Value 0.461 ). The overall incidence of crustation and adhesion is more in group $A$ than in group $B$ but it was also statistically not significant.

In conclusion, endoscopic endonasal DCR carries no significant difference of success rate whether it is with or without mucosal flap.

Key words: Endoscopy, Dacryocyctorhinostomy, flap, Surgery.
\end{abstract}

\section{Introduction}

$A$ cquired nasolacrimal duct common disorder and most authors believe that surgical intervention is the treatment of choice ${ }^{1}$. The intranasal approach for endoscopic dacryocystorhinostomy was first described and introduced by Caldwell in $1893^{1}$. John West in 1914 modified this technique by creating a bony window within the lacrimal and maxillary bones to clear the area of lacrimal sac and nasolacrimal duct into the middle meatus ${ }^{2,3}$. Rice first introduced the concept of endoscopic endonasal DCR in cadavers in 1988 and showed its feasibility as a good alternative to an external $\mathrm{DCR}^{4}$. McDonogh and Meiring in 1989 introduced endoscopic endonasal $\mathrm{DCR}^{5}$. The basic principle of the surgical treatment is to create a large bypass above the obstruction by connecting the lacrimal sac through a surgically made boney ostium to the nasal cavity has remained the same since it was described over a century ago ${ }^{6,7}$. Powered and mechanical endoscopic DCR was described by Peter-John Wormald in $2002^{8}$.

\section{Patients and methods}

This prospective, comparative study was carried on 39 patients who underwent endoscopic DCR and it was done in the period from July 2018 to July 2019 at Basrah Teaching Hospital in the department of otolaryngology. Patients were randomly divided into two groups: Group A (26 patients); are those in which the mucosal flap was not preserved. 
Group B (13 patients); the mucosal flap was preserved.

All patients were complaining from epiphora due to acquired NLDO for more than one year, they were assessed by the ophthalmologist and after exclusion of the other causes, patients were referred to otolaryngologist who did a thorough history taking and careful rhinological examination by rigid nasoendoscopy.

The exclusion criteria were: cases of congenital dacrocystitis, suspected presacal obstruction, coexisting nasal pathologies which could influence the outcome of the surgery, immune compromised patients, and any uncontrolled medical diseases.

All patients were informed about the nature of the operation, silicon stent placement and timing of removal which was after six weeks to six months postoperatively.

Surgical procedure: All surgeries were done under general anesthesia, in supine position with head elevated 15 degrees and tilted toward the surgeon. Surgery was carried out by using 0 degree endoscope. Lignocaine $2 \%$ with adrenaline 1:100000 was injected anterior and above the anterior attachment of middle turbinate. Circular incision was kept anterior to the uncinate process at the anterior maxillary line. The frontonasal process of maxilla, lacrimal crest and lacrimal bone were exposed. The frontonasal process of maxilla was removed by Kerrison punch forceps or drilling to expose the lacrimal sac adequately. The upper and lower punctum of the eye were dilated by Nettleship lacrimal punctum dilator and the Bowman lacrimal probe was passed through the punctum, canaliculi and lacrimal sac. The lacrimal sac then confirmed and its medial wall was incised by sickle knife or blade and partially removed (group A) or marsupialized (group B). In all patients, stenting was done.
The follow-up was done at one, three and six months postoperatively. Before the removal of the silicon tube, assessment of lacrimal patency was done by subjective method for improvement of epiphora whether present or absent and objective methods by fluorescein dye disappearance test and by checking of the new ostia in the nose with rigid nasoendoscope. After removal of the silicone stent, syringing of the lacrimal system through the inferior punctum with saline was done to confirm the patency, endoscopically or the patient have taste the salty saline.

Statistical package of social sciences version 23 was used to determine the difference between the results of the two groups in one, three and six months postoperatively. A P-value of $<0.05$ is considered to be statistically significant.

\section{Results}

In this study, the total number of patients was divided randomly into two groups: Group A (26 patients) and group B (13 patients). The total 39 patients were 36 females $(92.3 \%)$ and 3 males $(7.7 \%)$ with female to male ratio of $12: 1$. The age of patients ranged from 4 to 72 years with majority of studied patients belong to 2040 years age group. Epiphora was the most common preoperative symptom and was present in all patients in both groups, followed by recurrent lacrimal sac swelling, preiorbital swelling and lacrimal fistula. All patients were operated upon under general anesthesia. The mean operating time was $30 \pm 9$ minutes for group $\mathrm{A}$ and $35 \pm 4$ minutes for group B (the time of septoplasty and other concurrent surgery was not included).

In one month postoperative visit, the results are shown in table I where there was no statistical significant difference between the two groups regarding epiphora, crustation, adhesion and ostial patency. 
Table I: Postoperative comparison between groups A\&B in one month follow-up.

\begin{tabular}{|c|c|c|c|}
\hline Variable & $\begin{array}{c}\text { Group A } \\
\text { Number (\%) }\end{array}$ & $\begin{array}{c}\text { Group B } \\
\text { Number (\%) }\end{array}$ & P-Value \\
\hline Epiphora & $5 / 26(19.2)$ & $1 / 13(7.7)$ & 0.346 \\
\hline Crustation & $11 / 26(42.3)$ & $5 / 13(38.5)$ & 0.818 \\
\hline Adhesion & $12 / 26(46.2)$ & $3 / 13(23.1)$ & 0.163 \\
\hline Ostial patency & $25 / 26(96.2)$ & $13 / 13(100)$ & 0.474 \\
\hline
\end{tabular}

In three months postoperative visit, the results are shown in table II where there is no statistically significant difference between the two groups regarding epiphora, crustation, adhesion, and ostial patency.

Table II: Postoperative comparison between groups A\&B in three months follow-up.

\begin{tabular}{|c|c|c|c|}
\hline Variable & $\begin{array}{c}\text { Group A } \\
\text { Number (\%) }\end{array}$ & $\begin{array}{c}\text { Group B } \\
\text { Number (\%) }\end{array}$ & P-Value \\
\hline Epiphora & $4 / 26(15.4)$ & $1 / 13(7.7)$ & 0.498 \\
\hline Crustation & $1 / 26(3.8)$ & $1 / 13(7.7)$ & 0.608 \\
\hline Adhesion & $6 / 26(23.1)$ & $1 / 13(7.7)$ & 0.238 \\
\hline Ostial patency & $24 / 26(92.3)$ & $12 / 13(92.3)$ & 1.000 \\
\hline
\end{tabular}

In six months postoperative visit, the results are shown in table III, where there is statistically nonsignificant difference between the two groups regarding epiphora, crustation, adhesion, and ostial patency.

Table III: Postoperative comparison between groups A\&B in three months follow-up.

\begin{tabular}{|c|c|c|c|}
\hline Variable & $\begin{array}{c}\text { Group A } \\
\text { Number (\%) }\end{array}$ & $\begin{array}{c}\text { Group B } \\
\text { Number (\%) }\end{array}$ & P-Value \\
\hline Epiphora & $4 / 21(19)$ & $1 / 11(9.1)$ & 0.306 \\
\hline Adhesion & $3 / 21(14.3)$ & $0 / 11(0)$ & 0.188 \\
\hline ostial patency & $17 / 21(81)$ & $10 / 11(90.9)$ & 0.461 \\
\hline
\end{tabular}

\section{Discussion}

Historically, dacryocystorhinostomy (DCR) has been performed externally with very good outcome ${ }^{9}$. A growing clinical experience has confirmed the value of the endoscopic DCR technique in the management of nasolacrimal system obstruction and current literatures showed comparable success rates between endonasal and external approaches ${ }^{10}$. However, the importance of using the mucosal flap technique remains unclear because success rates appear to be reasonable with a variety of approaches. The Wormald technique ${ }^{8}$ emphasizes the creation and preservation of mucosal flaps with primary juxtaposition of mucosal edges, the goal being healing by primary intention. This technique, in their hands has been shown to produce a large and stable ostium with excellent functional outcome ${ }^{11}$. Other investigators have reported success while using a variety of techniques that do not preserve mucosal or lacrimal sac flaps ${ }^{12-15}$.

In the present study, the age of patients ranged from 4-72 years and the most affected age group was 21-40 which goes with a study done by Kamal et al ${ }^{16}$ that showed the mean age at presentation was 34 ranging from 4-75 years, however it is incomparable to Linberg et $\mathrm{al}^{17}$ in which the age of patients ranged from 14- 
74 years and the most affected age group was $41-50$ years. There was a declining trend towards both extreme of ages. This may be due to the fact that amount of lacrimal secretion is less in extreme of age $^{18}$.

The left side was affected in 25 patients $(64.1 \%)$, while the right side was affected in 14 patients $(35.9 \%)$ and this is comparable to study done by Tsirbas and Wormald $^{19}$ but incomparable to Navaneethan's ${ }^{20}$ study, however, there was no difficulty in proceeding the surgery depending upon the side of the procedure.

Our study showed that there was a female predominance, the females were $36(92.3 \%)$ and the males were $3(7.7 \%)$, with female to male ratio of 12:1 which agree with study done by Ambani et $\mathrm{al}^{21}$, Kamal et $\mathrm{al}^{16}$ and $\mathrm{Ji}$ et $\mathrm{al}^{22}$. The anatomical reason for female predominance is the narrow lumen of bony canal which was found to be the commonest site of obstruction in females $^{23}$. In addition, chronic dacryocystitis had been observed to be more common in women of low socioeconomic group due to their bad personal habits, long duration of exposure to smoke in kitchen and dust in external environment. In addition to that use of kajal and other cosmetics increase chance of transmission of infection ${ }^{24}$.

Regarding success rate, in the present study and after six months follow-up, the success rate was (17/21) $81 \%$ and (10/11) $90.9 \%$ for group A (without mucosal flap) and group B (with mucosal flap) respectively. This reflects that the mucosal flap preservation increases the success rate but with no statistically significant difference between the groups because the P-value was more than 0.05 . This result is comparable to Kansu et $\mathrm{al}^{25}$ who conducted a comparative study of surgical outcome of endoscopic DCR with or without mucosal flaps. The result indicated that the closure of bare bone with nasal mucosal flap and an anastomosis between the lacrimal sac mucosa and the nasal mucosa decreases the formation of granulation tissue, but there was no significant difference of success rate, $100 \%$ and $88.3 \%$ for each group; with and without mucosal flap respectively. Khalifa et $\mathrm{al}^{26}$ also conducted a prospective randomized controlled trial of total 80 procedures where an endoscopic DCR with mucosal flap had a higher (92.1\%) but nonsignificant difference in success rate when compared with endoscopic DCR without mucosal flap $(87.4 \%)$, and this also showed in accordance with our results. Parmar et $\mathrm{al}^{27}$ found that preserving the lacrimal and nasal mucosa through an endoscopic approach to treat nasolacrimal duct obstruction leads to a high success rate by controlled lining of the fistula with mucosal flaps which appears to prevent closure of the ostium, the success rate after one year follow-up was $83.33 \%$ vs 81.81 for with and without mucosal flap preservation respectively, but he did not point out the significant difference or P-value between the two groups. However $\mathrm{Ji}$ et $\mathrm{al}^{22}$ reported that preservation of mucosal flap associated with improved success rates with statistically significant improvement when compared with mucosal flap removal $98 \%$ vs $84 \%$ respectively and this agrees with our results that the mucosal flap preservation improves the success rate but disagrees in that this improvement is statistically significant. This may be due to larger sample size (total 120). Tai LM et $\mathrm{al}^{28}$ also found a small but significant association between preservation of a mucosal flap and a successful outcome of endoscopic DCR $(\mathrm{P}=0.035)$.

When we take the success rate for each group separately and compare it to similar studies, the overall success with both patency and symptom free is $81 \%(17 / 21)$ in group A (without flap) and this agrees with Navaneethan's ${ }^{20}$ study in which the success rate was $88 \%(23 / 26)$. 
Tsirbas and Wormald ${ }^{19}$ performed 104 endoscopic DCR with mucosal flap preservation and the surgery was successful in 93 cases $(89 \%)$ which is a similar to ours in group B (with mucosal flap) $90.9 \%(10 / 11)$. Telang et $\mathrm{al}^{29}$ found that preservation of lacrimal sac and nasal mucosa leads to marsupialization of lacrimal sac onto the lateral nasal wall with success rate of $96 \%$. Gurdeep et $\mathrm{al}^{30}$ in their study of powered endoscopic DCR with mucosal flaps achieved a success rate of $91.66 \%$. Goyal et $\mathrm{al}^{31}$ reported a success rate of endonasal DCR with mucosal flaps of $85.10 \%$ after 1 year follow-up.

Conclusion:

The closure of bare bone with nasal mucosal flap and an anastomosis between the lacrimal sac mucosa and the nasal mucosa improves the success rate of endoscopic DCR as well as decreases the formation of granulation tissue and synechea but there was no significant difference to that of mucosal flap sacrifying endoscopic DCR. So it is of no matter whether to preserve or to remove the mucosal flap.

\section{References}

1.Woog JJ, Kennedy RH, Custer PL, Kaltreider SA, Meyer DR, Camara JG. Endonasal dacryocystorhinostomy. Ophthalmology. 2001;108(12):2369-77.

2.Watkins LM, Janfaza P, Rubin PA. The evolution of endonasal dacryocystorhinostomy. Survey of ophthalmology. 2003;48(1):7384.

3.PA. C. Dacryocystorhinostomy. Trans Am Ophthalmol Soc. 1936;34::240-63.

4.Rice DH. Endoscopic intranasal dacryocystorhinostomy,A cadaver study. American Journal of Rhinology. 1988;2(3):127-8.

5.McDonogh M, Meiring J. Endoscopic transnasal dacryocystorhinostomy. The Journal of Laryngology \& Otology. 1989;103(6):585-7.

6.Toti A. Nuovo metado conservatore di radicale delle suppurazioni croniche del sacco lacrimale (dacriocystorhinostomia). Cli Mod Pisa. 1904:10:385-7.

7.Caldwell G. Two new operations for obstruction of the nasal duct, with preservation of the canaliculi. Am J Ophthalmol. $1893 ; 10: 189-92$.

8.Wormald PJ. Powered endoscopic dacryocystorhinostomy. The Laryngoscope. 2002;112(1):69-72.

9.Leong SC, MacEwen CJ, White PS. A systematic review of outcomes after dacryocystorhinostomy in adults. American journal of rhinology \& allergy. 2010;24(1):81-90.

10.Green R, Gohil R, Ross P. Mucosal and lacrimal flaps for endonasal dacryocystorhinostomy: a systematic review. Clinical Otolaryngology. 2017;42(3):514-20.

11.Mann BS, Wormald PJ. Endoscopic assessment of the dacryocystorhinostomy ostium after endoscopic surgery. The Laryngoscope. 2006;116(7):1172-4.

12.Simon GJB, Joseph J, Lee S, Schwarcz RM, McCann JD, Goldberg RA. External versus endoscopic dacryocystorhinostomy for acquired nasolacrimal duct obstruction in a tertiary referral center. Ophthalmology. 2005;112(8):1463-8.

13.Cokkeser Y, Evereklioglu C, Er H. Comparative external versus endoscopic dacryocystorhinostomy: results in 115 patients (130 eyes). Otolaryngology,Head and Neck Surgery. 2000;123(4):488-91.

14.Kennedy DW, Bolger WE, Zinreich SJ. Diseases of the sinuses: diagnosis and management: PMPH-USA; 2001

15.Yoon SW YY, and Lee SH. . Clinical results of endoscopic DCR using a microdebrider. Korean J Ophthalmol. 2006;20:1-6.

16.Saurabh Kamal MJA, and Akshay Gopinathan Nair. Outcomes of endoscopic dacryocystorhinostomy: Experience of a

fellowship trainee at a tertiary care center. Indian J Ophthalmol. 2016 64(9): 648-53.

17.Linberg JV MCS. Primary acquired nasolacrimal duct obstruction. A clinic pathological reports and biopsy technique. Opthalmo. Aug.1986; (8):1055-63.

18.Aniruddha Majumder MS, Chiranjib Das, Saumik Das, and Tapan kanti Hazra. Endonasal Dacryocystorhinostomy with Mucosal Flaps: Our Experience. Indian J Otolaryngol Head Neck Surg. 2013 Aug;65:371-5.

19.Tsirbas A WP. Mechanical endonasal dacryocystorhinostomy with mucosal flaps. Br J Ophthalmol. 2003;87(1):43-7.

20.Navaneethan N. Endoscopic dacryocystorhinostomy without mucosal flap. Bangladesh J Otorhinolaryngol. 2013;19(1): 41-5.

21.Ambani K, Suri N, Parmar H. Study of success rates in endoscopic dacrocystorhinostomy with and without stenting. International Archives of Integrated Medicine. 2015;2(4):52-6.

22.Ji QS ZJ, Tu YH, Wu WC. New mucosal flap modification for endonasal endoscopic dacryocystorhinostomy in Asians. Int J Opthalmol. 2012;5(6):704-7.

23. Grover AK BA. Modern Opthalmology. First Edition ed1994.

24.SW. G. Etiology of dacryocystitis and epiphora. Arch Opthalmol. 1942;27:167-88.

25.Kansu L, Aydin E, Avci S, Kal A, Gedik S. Comparison of surgical outcomes of endonasal dacryocystorhinostomy with or without mucosal flaps. Auris Nasus Larynx. 2009;36(5):555-9.

26.Khalifa MA, Ragab SM, Saafan ME, El-Guindy AS. Endoscopic dacryocystorhinostomy with double posteriorly based nasal and lacrimal flaps: a prospective randomized controlled trial. Otolaryngology--Head and Neck Surgery. 2012;147(4):782-7.

27.Sonu Parmar Bharti Solanki, Ankit Goyal Endonasal dacryocyctorhinostomy. Paripex-Indian Journal Of Research. 2016;5(8):496-8

28.Evelyn Tai Li Min JMPT, Wan Hazabbah Wan Hitam ,Ramiza Ramza, Baharudin Abdullah, Adil Hussein. Effect of stenting and mucosal flap preservation onoutcome of endoscopic dacryocystorhinostomy. Int Eye Sci. 2014;14:381-5.

29.Telang R, Maheshwary M, Joshi S. A study of endoscopic endonasal dacrocystorhinostomy with mucosal flap technique. J Evid Based Med Healthcare. 2015;2:8050-9.

30.Gurdeep S. Powered endoscopic dacryocystorhinostomy with mucosal flaps without stenting. Med J Malaysia. 2008;63(3):237.

31.Rashmi Goyal SG. Analysis of 104 Cases of Endonasal Dacryocystorhinostomy in a Tertiary Care Hospital: A Prospective Study. Indian J Otolaryngol Head Neck Surg. 2014 66(1):102-5. 